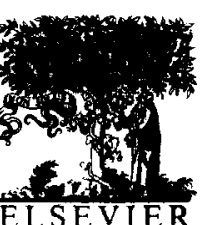

\title{
HEATH Policy
}

Health Policy 31 (1995) 53-65

\section{The introduction of deductibles for prescription drugs in a national health insurance: compulsory or voluntary?}

\author{
F.M. Bakker, R.C.J.A. van Vliet*, \\ Department of Health Policy and Management, School of Medicine and Health Sciences, Erasmus \\ University, P.O. Box 1738, 3000 DR Rotterdam, The Netherlands
}

Received 24 June 1994; revision received 19 September 1994; accepted 26 September 1994

\begin{abstract}
We consider a situation of full insurance coverage for prescription drugs where, at a certain point in time, people are given the opportunity to take a deductible in exchange for a lower premium. Four determinants of this premium reduction can be considered: expected out-ofpocket payments, adverse selection effects, moral hazard effects, and administration costs. The purpose of this study is to analyse the first two determinants. Survey data of 17242 insureds in the Netherlands have been used for this research. Results show that the expected out-of-pocket expenditures in case of a certain deductible amount depend strongly on age and gender. People in poor health could be given a larger premium discount if they would take a deductible than those in good health. This implies that a uniform premium discount would induce adverse selection. The effects of such selection have been simulated by using a survey question about the preference to take a general deductible. If the premium reductions for policies with a deductible are adjusted for age and gender, the selection effect will halve but will still be substantial. We conclude that, in the situation considered here, it is largely immaterial whether deductibles are compulsory or voluntary, provided premium reductions are allowed to depend on relevant risk factors.
\end{abstract}

Keywords: Deductibles; Prescription drugs; Out-of-pocket expenditures; Adverse selection

\section{Introduction}

Recently in many countries health care reforms have been proposed or implemented in order to improve efficiency in health care. As an element of the Dutch

* Corresponding author. 
health care reforms, prescription drugs are completely covered for the whole population by the Exceptional Medical Expenses Act (AWBZ) since January 1, 1992. The premium for the AWBZ is largely income related. In addition each person pays a small premium that is independent of risk. In the Netherlands the increasing costs of prescription drugs are a major concern for the Department of Health. In order to control costs, the introduction of a limited deductible for prescription drugs has been proposed by the government.

In the case of a deductible insureds have to pay the costs of drugs themselves up to the deductible amount. Drug costs above that specific deductible amount are paid by the insurer. One of the major policy issues concerning the introduction of deductibles is whether these should be either compulsory or voluntary. In this article we will deal with this question.

In case of a deductible the insured will pay a lower premium. Generally speaking, four determinants of the premium reduction can be considered in case of a voluntary deductible: (1) expected out-of-pocket payments, (2) moral hazard effects, (3) adverse selection effects, and (4) administration costs. In the case of a compulsory deductible the third component is not relevant.

From the insurer's point of view out-of-pocket payments form avoided costs. The expected amount of out-of-pocket expenses depends on the risk the insured represents. Given a certain deductible amount, high risks (those in poor health) will have higher out-of-pocket expenditures than low risks (healthy). Therefore, high risks could be given a higher premium discount in the case of a deductible. It has yet to be decided whether the premium discounts will be allowed to be risk-related. This is an important choice between either high risks receiving a larger premium discount as a compensation for their higher expected out-of-pocket expenditures, or high risks in fact subsidizing low risks as a consequence of the uniform premium discount. This cross subsidization can be sustained only by means of regulation of the premium discount.

The second determinant of the premium reduction is the effect of moral hazard $[1-7]$. This is the effect of insurance by which people consume more than they would do without insurance because they do not have to pay all costs themselves. The third determinant, (the effects of) adverse selection, is the tendency of high risks to be more likely to buy insurance or to buy larger amounts than low risks [8-10]. In general the healthy will take a deductible [11]. Adverse selection may cause a competitive insurance market to be unstable [12]. If selection effects are not taken into account when premium discounts are calculated, the discounts for those who take a deductible will be too large because these are in general the low risks. In that case, insurers will make a loss on the deductible policies: the premium reduction will on average be larger than the out-of-pocket payments. This may start a downward premium reduction spiral so that in the end the premium reduction will be zero, because at every level of the premium discount the group of relatively good risks that will conclude the policy with a deductible is getting smaller and more selective $[13,14]$. However, with a hypothetical premium reduction of zero, the same situation is achieved as the current, i.e. complete coverage.

The purpose of this study is to analyse the expected out-of-pocket expenditures 
and adverse selection effects as a result of the introduction of deductibles for costs of prescribed drugs in a situation of full coverage like the present Dutch AWBZ. We will concentrate on two questions: 'Should the premium reductions be risk-related or uniform?' and 'Is it possible to safeguard insurers against adverse selection effects in the case of voluntary deductibles?'. Furthermore, the expected out-of-pocket expenses in the case of compulsory and voluntary deductibles will be compared.

In section 2 we describe the data and methods. The results are presented in section 3. Firstly, we discuss the issue of the introduction of a compulsory deductible, i.e. the case where adverse selection effects are absent because everybody is subjected to a deductible. Secondly, selection effects are analysed in the case of voluntary deductibles. These effects are presented in general and per age/gender group. In section 4 the policy relevance is discussed. Finally, in section 5 conclusions are drawn.

\section{Data and methods}

In this study, survey data of 17242 insureds of a large private health insurance organization in the Netherlands were used. The survey, held in 1976, contained questions about: money spent on pharmaceuticals prescribed by general practitioners (GPs) and specialists, the preference to take a general deductible, health status, and socio-economic characteristics. Adjustments were applied to make all insureds comparable with respect to their insurance coverage, to transform drug costs data from 6 to 12 months, and to account for inflation ${ }^{1}$. Ultimately, the data analysed can be considered as an approximation of 1993 expenditure data on drugs prescribed by GPs and specialists. Over-the-counter drugs are not included because these are not covered by the AWBZ.

The two-part model [3] is used to estimate the expected out-of-pocket payments. The first part of the model is an analysis of the probability of drug use by means of a probit equation. The second part is an analysis of the logarithm of the non-zero drug expenditures via a linear regression. Subsequently, a mathematical approach is used to calculate for a number of deductible amounts the expected amount of drug costs for the insurer and the expected out-of-pocket expenses for the insured. This approach is an adaptation of Klugman [15] and is described in the Appendix.

\section{Results}

Firstly, we will discuss the case of the introduction of a compulsory deductible (i.e. the case where adverse selection is not possible) in a situation of full coverage. The resulting expected out-of-pocket expenses are the basis for premium discounts. Secondly, selection effects are presented in the case of the introduction of voluntary deductibles.

\footnotetext{
${ }^{1}$ A statistical description of the drug costs data adjustments is available from the authors.
} 


\subsection{Compulsory deductibles}

Fig. 1 shows the expected out-of-pocket expenditures (premium discounts) averaged over the entire sample as a consequence of the introduction of a compulsory deductible starting from full coverage. The average costs of drugs prescribed by GPs and specialists are Dfl 308 (= 175 USD, August 1994). Of course with an infinite deductible amount (i.e. no coverage at all) the average out-of-pocket expenditures equal the premium for an insurance policy without deductible, i.e. Df1 308, ignoring loading fees.

With a compulsory deductible of Dfl 100 the expected out-of-pocket expenditures are Dfl 53 per individual. This implies that the premium could be reduced from Dfl 308 to Dfl $255(=308-53)$. The expected drug costs above the deductible of Dfl 100 are thus Dfl 255, which are for account of the insurer. For larger deductible amounts the premium discount will be larger by a decreasing rate.

To this point we have considered only compulsory deductibles with a uniform premium discount. But what are the consequences for men versus women, for example? The expected drug costs differ per gender. On average women have about $46 \%$ higher costs than men (Dfl 367 vs. Dfl 251). With a compulsory deductible of Dfl 500 , women will have expected out-of-pocket payments of Dfl 188 and men of Dfl 140. Without a differentiation according to gender the expected out-of-pocket payments are Dfl 163 (Fig. 1). So, the introduction of a compulsory deductible of Dfl 500 with a uniform premium reduction of Dfl 163 would result in an expected advantage of Dfl 23 for men (= premium reduction minus expected out-of-pocket expenses $=163-140$ ) and an expected disadvantage of Dfl 25 for women (163-188). From the insurer's point of view, insuring a male generates an expected loss of Dfl 23, while insuring a female generates an expected contribution to profit of Dfl 25. With larger deductible amounts these differences will increase further. Thus, the con-

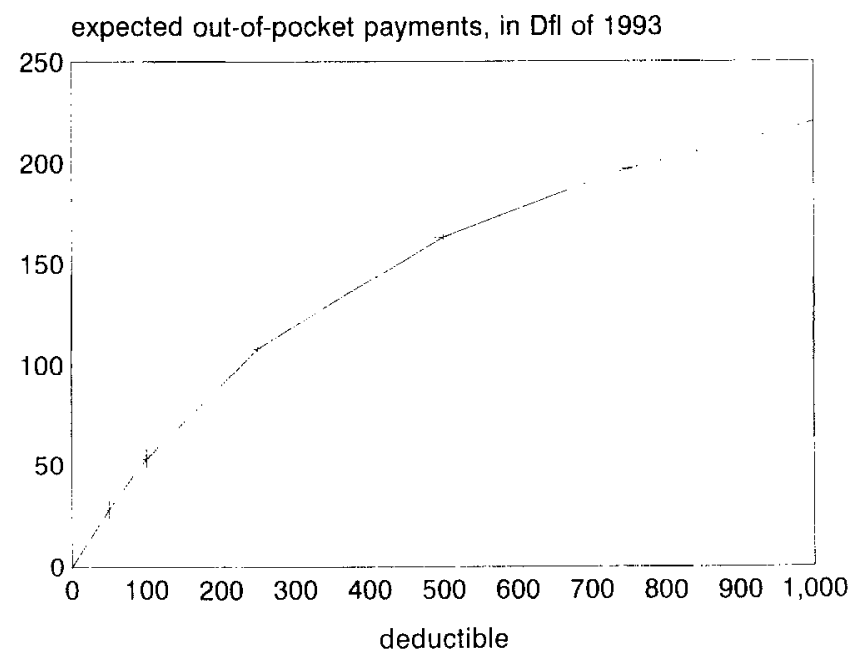

Fig. 1. The expected out-of-pocket payments per compulsory deductible. 
sequence of such a rigid premium structure would be that women would have higher out-of-pocket payments than men which are not compensated by higher premium discounts. This constitutes an incentive for risk selection in the case of voluntary deductibles.

Another obvious distinction is a differentiation according to age. Table 1 shows that drug costs are strongly related to age. People above the age of 40 have higher costs than average. The same holds for their expected out-of-pocket expenses in case of a deductible. In comparison with a uniform premium reduction, individuals up to 40 years of age, with less than average out-of-pocket expenses, will have a disadvantage if the premium reductions are age-related. Finally, the expected out-ofpocket expenditures per age/gender category in case of a compulsory deductible of Dfl 500 are depicted in Fig. 2. It shows clearly that, from an actuarial point of view, the premium discount should increase with age. Generally, the same argument applies for people in poor health.

Other arguments may be involved when insurers determine their premium reductions. For example: are there possibilities to attract good risks? In this manner adverse selection [16] might take place on the basis of different expected costs above the deductible amount or it might take the form of attracting people with low costs

Table 1

Expected costs above and below a compulsory deductible

\begin{tabular}{lcrrrrr}
\hline & Age & \multicolumn{2}{l}{ Deductible } & & & \\
\cline { 2 - 6 } & & 0 & 100 & 250 & 500 & 1000 \\
\hline Expected costs above & $0-9$ & 140 & 92 & 55 & 29 & 11 \\
deductible (insured) & $10-19$ & 99 & 67 & 42 & 23 & 10 \\
& $20-29$ & 207 & 156 & 108 & 66 & 32 \\
& $30-39$ & 235 & 181 & 128 & 80 & 39 \\
& $40-49$ & 348 & 289 & 223 & 155 & 87 \\
& $50-59$ & 501 & 437 & 360 & 271 & 171 \\
& $60-69$ & 761 & 692 & 601 & 486 & 339 \\
& $70-79$ & 862 & 787 & 687 & 557 & 390 \\
& $80+$ & 1014 & 931 & 819 & 671 & 476 \\
& & & & & & \\
& Average & 308 & 255 & 200 & 144 & 88 \\
\hline Expected costs below & $0-9$ & 0 & 48 & 85 & 111 & 128 \\
deductible (insurer) & $10-19$ & 0 & 32 & 57 & 76 & 89 \\
& $20-29$ & 0 & 51 & 99 & 140 & 175 \\
& $30-39$ & 0 & 54 & 108 & 156 & 196 \\
& $40-49$ & 0 & 59 & 126 & 194 & 261 \\
& $50-59$ & 0 & 64 & 141 & 230 & 329 \\
& $60-69$ & 0 & 69 & 160 & 275 & 422 \\
& $70-79$ & 0 & 75 & 175 & 304 & 471 \\
& $80+$ & 0 & 83 & 195 & 343 & 538 \\
& & & & & & \\
& Average & 0 & 53 & 108 & 163 & 220 \\
\hline
\end{tabular}




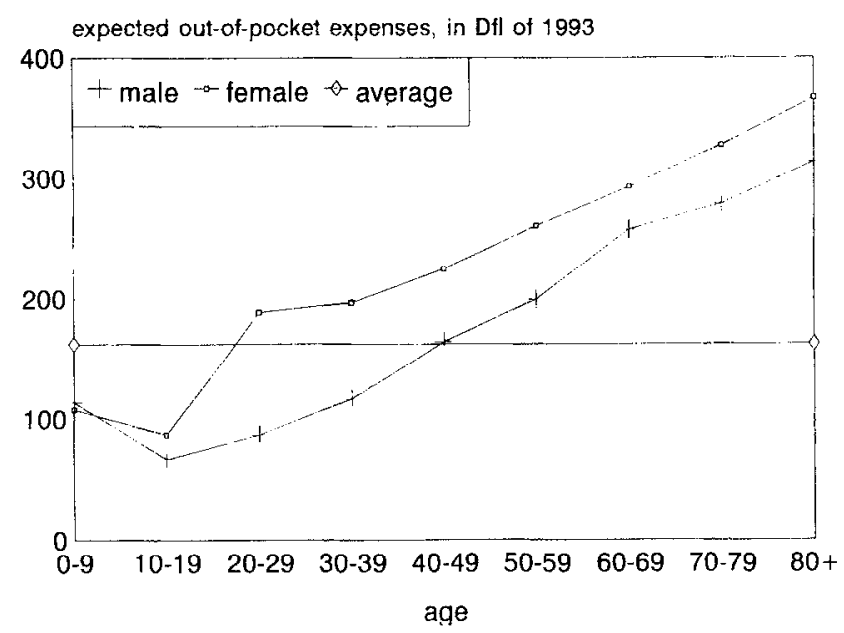

Fig. 2. Expected out-of-pocket expenses per age/gender category: a compulsory deductible of DI 500.

for other kinds of health care. In this case insurers may opt to give low risks (healthy people) a higher than actuarially fair premium reduction when they take a deductible, while the high risks would receive a lower than actuarially fair premium reduction. This would attract low risks and repulse high risks.

\subsection{Voluntary deductibles}

With a voluntary deductible, adverse selection could become a problem. In this study selection effects are inferred from the survey question about the preference for a general deductible. We assumed that this question could be seen as a proxy for selection. Some limitations can be mentioned. First, it is the answer to a survey question and not a real choice. Second, the question read: 'Would you like to have a health insurance plan with a deductible if you would get an appropriate premium reduction?'. Therefore, the answers should be interpreted as an indication whether one generally liked the idea of a deductible because a specific deductible amount and premium reduction are not mentioned. So, for every hypothetical deductible amount, we assumed the same selection effects. Furthermore, the survey question was only asked at the family level, i.e. the situation in which the deductible relates to all family members. Therefore, the head of the household and his/her partner and children had the same derived answer. In the case of individual deductibles, selection effects can be expected to be larger than with family deductibles because family policies are a form of risk-pooling [17]. Finally the question referred to a general deductible and not a drug-specific one. Maybe individuals can predict their drug costs better than their total health care costs and thus selection effects will be larger with a deductible for drugs only. For these reasons the results of our simulation analyses should be viewed as indications of the problems that are likely to arise when voluntary deductibles are introduced in a situation of complete coverage. 
About half the policy holders answered the question about the general deductible in the affirmative. As expected, persons that do not want a deductible have substantially higher costs: Dfl 386 vs. Dfl 222 (deductible group). We define the adverse selection effect as the difference between the average total drug costs of the no-deductible group and the deductible group. In this definition selection is not based on the difference in expected out-of-pocket payments between the two groups because this difference depends on the deductible amount. In this case the selection effect is Dfl $164(=386-222)$. In relative terms this is $53 \%(=164 / 308 \times 100 \%)$ of the overall mean costs.

If insurers would not take adverse selection effects into account, the premium discounts can be based on the overall expected out-of-pocket expenditures. Then the insurers would soon discover that these premium discounts are too high as a consequence of selection. Actually, with a deductible of Dfl 500, the premium discount should be Dfl 136 instead of Dfl 163 [the expected out-of-pocket expenses of the deductible-group (see Fig. 3) instead of the expected out-of-pocket expenses in the case of a compulsory deductible of Dfl 500 , i.e. without risk selection effects]. So, next year insurers will offer a premium reduction of for example Dft 136. If individuals have the choice each year whether to take a deductible, then the relatively high risks who originally would have chosen a deductible of Dfl 500 with a premium reduction of Dfl 163, will opt for full coverage if the premium reduction is lowered to Dfl 136. The same argument can be repeated for the following years, which ultimately might result in a premium reduction of zero.

For a risk-neutral individual the policy choice results from comparing the premium reduction with the expected out-of-pocket expenses. However, we could not simulate this dynamic process because we do not know in which way insureds will make their choice in reality, i.e. with specific deductible amounts and premium discounts. So, all results with regard to adverse selection effects are based on the once-only survey question and are consequently hypothetical.

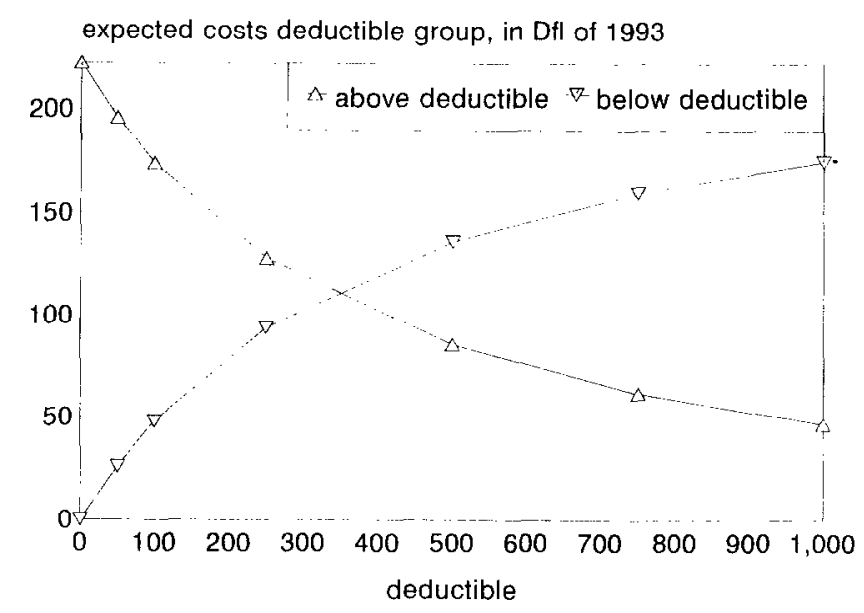

Fig. 3. Expected costs above and below deductible, with selection. Note: total expected costs deductible group Df 222; no deductible group, Dfl 386. 
If the premium discounts are differentiated according to gender, the adverse selection effects still remain substantial. For men the difference in drug costs between the no-deductible and deductible group is Dfl $136(=318-182)$ or $54 \%(136 / 251 \times$ $100 \%)$. For women these figures are Dfl $188(=454-266)$ and $51 \%$ $(188 / 367 \times 100 \%)$, respectively. Perhaps the reason for this small decline is the measurement method: the survey question referred to a family deductible and not to an individual deductible, so, in spite of different expected drug costs for men and women, the derived answer on the survey question is the same for male and female belonging to the same family.

Table 2 presents the adverse selection effects with regard to age categories. This table contains the expected costs in general as well as for the no-deductible and deductible groups. The differentiation according to age results in a substantial decline of the selection effect. In money terms this effect reduces from Dfl 164 to Dfl 79 (figures weighted with the number of insureds per age category). This reduction is achieved because relatively many young insureds have expressed a preference for a deductible. It remains to be seen if the same pattern can be recognised in a situation when the premium reductions are age-related. Finally, the expected out-of-pocket expenditures for a deductible of Dfl 500 per age/gender are depicted in Fig. 4. Of course the expected out-of-pocket expenses for people who do not want a deductible are only hypothetical. Thus, these simulated expenses have to be understood as if the no-deductible group would still be obligated to take a deductible of Dfl 500 too.

The interaction between age and gender results in a further decrease of the relative risk selection effect to $23 \%$. This percentage is the mean (weighted by number of insureds) selection effect percentages of the 18 age/gender groups. The selection effect is still substantial and probably would have been even bigger had the survey question referred to the individual level instead of family level and specifically to drug costs instead of total health care costs.

\section{Policy relevance}

In the Netherlands prescribed drugs are completely covered for the whole population by the AWBZ (Exceptional Medical Expenses Act). In order to control costs, the introduction of a deductible for prescription drugs has been proposed by the

Table 2

Drug costs per age category, with selection

\begin{tabular}{lrrrrrrrrrr}
\hline \multicolumn{1}{l}{ Age group } \\
\cline { 2 - 10 } & $0-9$ & $10-19$ & $20-29$ & $30-39$ & $40-49$ & $50-59$ & $60-69$ & $70-79$ & $80+$ \\
\hline Average drug costs & 140 & 99 & 207 & 235 & 348 & 501 & 761 & 862 & 1014 \\
No-deductible group & 159 & 112 & 227 & 268 & 399 & 559 & 808 & 894 & 1036 \\
Deductible group & 124 & 88 & 182 & 208 & 293 & 415 & 636 & 706 & 876 \\
Selection effect (Df1) & 35 & 24 & 45 & 60 & 106 & 144 & 172 & 188 & 160 \\
Selection effect \%a & 25 & 24 & 22 & 26 & 30 & 29 & 23 & 22 & 16 \\
\hline
\end{tabular}

${ }^{a}$ As a percentage of average costs per age group. 


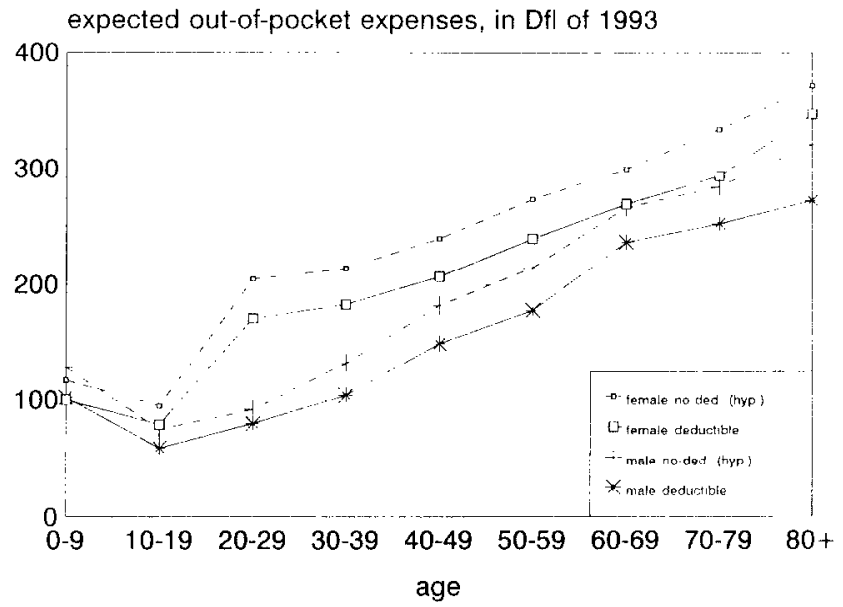

Fig. 4. Expected amount of out-of-pocket expenses: deductible/no-deductible group per age/gender (hypothetical deductible of Df 500). Note: the expected out of pocket expenses of the no-deductible group are hypothetical.

government. Several issues have to be decided upon, e.g. whether deductibles should be compulsory or voluntary, whether supplemental insurance should be allowed in case of a compulsory deductible, and whether premium reductions offered by insurers may be risk-related. Here we consider the possible premium reductions in case of a deductible of Dfl 500 .

\subsection{Compulsory deductible (Dfl 500)}

Option 1 is the case of a uniform premium reduction of Dfl 163 (independent of risk). The consequences are that young people $(<30$ years old) will have expected out-of-pocket expenses of about Dfl 100 and people of 60+ years old of about Dfl 300 (see Fig. 2). For a diabetic the out-of-pocket expenses will be very often Dfl 500. This raises questions about fairness $[18,19]$. Option 2 with a compulsory deductible is risk-related premium reductions. For example with a differentiation only according to age the possible premium reductions can in principle be the same as the expected out-of-pocket expenses (see Table 1). With completely risk-related reductions a diabetic should receive a premium discount of nearly Dfl 500 in the case of a deductible of Dfl 500 . So, an important choice that the government has to make is whether or not to allow risk-related premium reductions, and if so, on which risk factors the premium reductions may depend.

If supplemental insurance is allowed, selection might take place for the supplemental insurance with a uniform premium. This may cause an upward premium spiral so that in the end the premium for the supplemental insurance will be Dfl 500 . A risk-related premium for the supplemental insurance may prevent this selection effect to occur. 


\subsection{Voluntary deductible (Dfl 500)}

The options are the same as with a compulsory deductible. First we consider the same premium reduction for everyone. Adverse selection will result in premium reductions that are lower than the overall expected out-of-pocket expenses, because in general only the good risks will choose a deductible. However, this may cause a downward premium reduction spiral so that in the end the premium reduction will be zero, because at every premium discount level the relatively bad risks will not conclude the policy with a deductible. Option 2 is risk-related premium reductions. If the government allows the insurers to differentiate the premium reductions, then a diabetic can receive a premium discount of Dfl 500 and a very healthy young man Dfl 50 for example. Then, everyone has a real choice whether or not to take a deductible.

So, if the government wants a compulsory deductible for prescribed drugs, then the premium reductions should be risk-related to compensate for the different expected out-of-pocket expenses per individual. In the case of voluntary deductibles the same argument about fairness can be mentioned. Besides, risk-related premium reductions safeguard insurers against the effects of selection.

\section{Conclusion}

In this study we analysed the expected out-of-pocket expenditures and adverse selection effects as a result of the introduction of deductibles for costs of prescribed drugs in a situation of full coverage. For the estimation of the adverse selection effects in case of deductibles for drug costs we used survey data on drug expenditures and on the preference for a general deductible. The data on drug expenditures used were corrected for differences in insurance coverage, were transformed from halfyear data to 1-year data, and a correction for inflation was applied. The answers to the survey question about a deductible is interpreted as an indication whether one generally liked the idea of a deductible. This question was only asked at the family level, i.e. the situation in which the deductible relates to all family members, and it referred to a general deductible and not a drug-specific one.

For these reasons the results of our analyses should be viewed as an indication of the problems that are likely to arise when compulsory/voluntary deductibles with uniform/risk-related premium discounts are introduced in a situation of complete coverage.

Total drug costs are strongly related to age. Above the age of 20 drug costs increase approximately linear. People in the age category 50-59 have costs that are on average about twice as high as those in the age group of 30-39. Furthermore women have higher mean costs than men. The age group of 20-39 shows a gender difference in drug costs of a factor 2 . Of course these differences in drug costs have implications for the expected out-of-pocket expenditures in case of a deductible. With a compulsory deductible and a uniform premium reduction the elderly (and unhealthy) have a disadvantage: in general the premium reduction is not big enough to compensate the expected out-of-pocket expenses.

With voluntary deductibles a large difference in average drug costs has been found 
between persons who prefer a deductible and those who do not want a deductible, namely Dfl 222 for the deductible group and Dfl 386 for the no-deductible group. We defined the relative adverse selection effect as the difference between the expected average drug costs of the no-deductible and deductible groups divided by the average drug costs of both groups together. After correction for age/gender the selection effect reduces from about 0.53 to 0.23 . This still seems substantial and it remains to be seen if this will be sufficient to prevent risk selection. However with other characteristics (for example health status variables) the selection effect should reduce further.

In practice, people may not often change from the no-deductible group to the deductible group and vice versa because of material and immaterial transaction costs. Further, insurers could introduce a waiting period for switching to another insurance policy. This will protect them somewhat against calculated behaviour for planned or easily foreseen drug costs.

In conclusion, we found that when deductibles are introduced in a situation of full coverage, an age/gender-related premium discount structure will give a more stable insurance market than a uniform premium discount. As this holds for both compulsory and voluntary deductibles, the important choice for the politicians should be between uniform and risk-related premium discounts, and not so much between compulsory and voluntary.

\section{Acknowledgements}

The authors would like to thank Wynand van De Ven and an anonymous referee for helpful comments on an earlier version of this paper.

\section{Appendix}

The statistical method used for the calculation of the expected out-of-pocket expenses is the two-part model. First some variables are introduced:

$$
\begin{aligned}
& Y \quad=\text { drug costs (individual) } \\
& \mathrm{P}(Y>0)=\text { probability of non-zero drug costs } \\
& Y^{\prime} \quad=Y \mid Y>0 \\
& Y_{d l} \quad=\left[\begin{array}{cl}
Y & \text { if } Y \leq d \\
d & \text { if } Y>d
\end{array}=\text { drug costs below the deductible }(d \mid)\right. \\
& Y_{d \downarrow}=\left[\begin{array}{cc}
0 & \text { if } Y \leq d \\
Y-d & \text { if } Y>d
\end{array}=\text { drug costs below the deductible }\left(d^{\dagger}\right)\right. \\
& Y=Y_{d l}+Y_{d l}
\end{aligned}
$$


The expected values of $Y, Y_{d l}$, and $Y_{d l}$ are:

$$
\begin{aligned}
& E(Y)=\mathrm{P}(Y>0) \times E(Y) \\
& \begin{aligned}
& E\left(Y_{d 1}\right)=E(Y)-E\left(Y_{d 1}\right) \\
& \text { with } E\left(Y_{d 1}\right)=\mathrm{P}(Y>0) \times \mathrm{P}\left(Y^{\prime}>d\right) \times\left[E\left(Y^{\prime} \mid Y^{\prime}>d\right)-d\right] \\
& \text { or } E\left(Y_{d 1}\right)=\mathrm{P}(Y>0) \times{ }_{d} \int^{\infty}\left(y^{\prime}-d\right) \times \mathrm{f}\left(y^{\prime}\right) \delta y^{\prime} \\
&=\mathrm{E}(Y)-\mathrm{P}(Y>0) \times\left\{\int^{\infty} y^{\prime} \times \mathrm{f}\left(y^{\prime}\right) \delta y^{\prime}+d \times[1-\mathrm{F}(d)]\right\}
\end{aligned}
\end{aligned}
$$

So far, no assumptions are made about the distribution. Assuming - as is customary in analyses of health care expenditures - that $Y^{\prime}$ has a lognormal distribution with parameters $\mu$ and $\sigma$, gives the following derivations:

$$
\begin{aligned}
& E(Y)=\mathrm{P}(Y>0) \times \exp \left(\mu+0.5 \sigma^{2}\right) \\
& E\left(Y_{d l}\right)=E(Y)-E\left(Y_{d 1}\right) \\
& \quad \text { with: } E\left(Y_{d 1}\right)=E(Y) \times[1-\Phi(c-\sigma)]-\mathrm{P}(Y>0) \times d \times[1-\Phi(c)],
\end{aligned}
$$

where $c=[\log (d)-\mu] / \sigma$ and $\Phi$ the cumulative standard normal distribution function.

\section{References}

[1] Harris, B.L., Stergachis, A. and Ried, L.D., The effect of drug co-payments on utilization and cost of pharmaceuticals in a Health Maintenance Organization, Medical Care, 28 (1990) 907-917.

[2] Huttin, C., The use of prescription charges, Health Policy, 27 (1994) 53-73.

[3] Leibowitz, A., Manning, W.G. and Newhouse J.P., The demand for prescription drugs as a function of cost-sharing, Social Science and Medicine, 21 (1985) 1063-1069.

[4] Manning, W.G., Newhouse, J.P, Duan, N., Keeler, E.B., Leibowitz, A. and Marquis M.S., Health insurance and the demand for medical care: evidence from a randomized experiment, American Economic Review, 77 (1987) 251-277.

[5] Nelson, A.A., Reeder, C.E. and Dickson, W.M., The effect of a medicaid drug copayment program on the utilization and cost of prescription services, Medical Care, 22 (1984) 724-736.

[6] O'Brien, B., The effect of patient charges on the utilisation of prescription medicines, Journal of Health Economics, 8 (1989) 109-132.

[7] Pauly, M.V., Taxation, health insurance, and market failure in the medical economy, Journal of Economic Literature, 24 (1986) 629-675.

[8] Browne, M.J., Evidence of adverse selection in the individual health insurance market, The Journal of Risk and Insurance, 59 (1992) 13-33.

[9] Marquis, M.S. and Phelps, C.E., Price elasticity and adverse selection in the demand for supplementary health insurance, Economic Inquiry, 25 (1987) 299-313.

[10] Wolfe, J.R. and Goddeeris, J.H., Adverse selection, moral hazard, and wealth effects in the Medigap insurance market, Journal of Health Economics, 10 (1991) 433-459.

[11] Van de Ven, W.P.M.M. and Van Praag, B.M.S., The demand for deductibles in private health insurance, Journal of Econometrics, 17 (1981) 229-252.

[12] Rothschild, M. and Stiglitz, J., Equilibrium in competitive insurance markets: an essay on the economics of imperfect information, Quarterly Journal of Economics, 90 (1976) 629-649. 
[13] Feldman, R. and Dowd, B., Must adverse selection cause premium spirals?, Journal of Health Economics, 10 (1991) 349-357.

[14] Marquis, M.S., Adverse selection with a multiple choice among health insurance plans: A simulation analysis, Journal of Health Economics, 11 (1992) 129-151.

[15] Klugman, S.A., Loss distributions: estimation, large sample theory, and applications. In F. de Vylder et al. (Eds.), Premium Calculation in Insurance, Reidel Publishing Company, 1984, pp. 263-284.

[16] Van de Ven, W.P.M.M. and Van Vliet, R.C.J.A., How can we prevent cream skimming in a competitive health insurance market? The great challenge for the 90's. In P. Zweifel and H.E. Frech III (Eds.), Health Economics Worldwide, Kluwer Academic Publishers, The Netherlands, 1992. pp. $23-46$.

[17] Keeler, E.B., Relles, D.A. and Rolph, J.E., The choice between family and individual deductibles in health insurance policies, Journal of Economic Theory, 16 (1977) 220-227.

[18] Schulenburg, J.-M. Graf v.d., Germany: Solidarity at a price, Journal of Health Politics, Policy and Law, 17 (1992) 715-738.

[19] Stone, D.A., The struggle for the soul of health insurance, Journal of Health Politics, Policy and Law, 18 (1993) 287-317. 